\title{
La adición del empleo del DVD como medio audiovisual y documento electrónico en la modalidad de Testamento Cerrado prescrito en el Código Civil actual \\ Jessica Pilar Hermoza Calero* http://dx.doi.org/10.21503/lex.v9i8.404
}

* Doctora en Derecho por la Universidad Inca Garcilazo de la Vega, Maestra en Derecho Civil por la Universidad Inca Garcilaso de la Vega, con estudios concluidos en Maestría en Investigación y Docencia Universitaria, conciliadora extrajudicial en materia de Derecho Civil, profesora de la Facultad de Derecho y Ciencia Política de la Universidad Alas Peruanas. 



\section{Introducción}

El objetivo del presente trabajo es dar una respuesta afirmativa a la interrogante según la cual es posible la admisión del uso del DVD como documento idóneo en la modalidad de Testamento Cerrado prescrito en el Código Civil actual. Con ello, tratamos de hacer más accesible a la población el uso de la figura del testamento, brindándole la seguridad jurídica respectiva, y tomando en cuenta que, en nuestra sociedad, los procesos de comunicación audiovisual ocupan un importante lugar.

Prácticamente, en todas nuestras actividades, los mensajes transmitidos por estos medios condicionan nuestros hábitos. Hasta en los aspectos de la vida cotidiana más insignificantes se practican estos avances, como son la grabación de videos domésticos y la fotografía.

Con el tiempo, cada vez más son las personas que dan un paso al frente y comienzan a utilizar las nuevas herramientas digitales, aprovechando las mejoras con respecto a los métodos tradicionales y llevando cada tarea a un nivel superior, con más calidad y con posibilidades únicas.

De esta manera, se intenta que el escaso uso que se da al testamento en nuestra sociedad peruana actual como medio para la transmisión sucesoria sea mucho más frecuente. Se quiere evitar así la producción de gran cantidad de procesos de Sucesión Intestada y de División y Partición que resultan onerosos para los herederos respecto de la economía familiar y del tiempo empleado en ellos. 


\section{Algunos datos históricos sobre testamento y medios electrónicos. Principios Generales del Derecho Sucesorio Romano y Germánico y su influencia en el Derecho Hispano}

En el Derecho Romano, a la muerte del pater familias, los hijos (e hijas) a partir de este momento son sui iuris. Inicialmente, sólo el padre puede causar herencia (por esto se habla de causante o de cuius). A partir de ese momento, ocupan el lugar del padre, son heredes suis o herederos legítimos (o necesarios) y adquieren "por derecho» la condición, desde la muerte del cuius, mediante el ofrecimiento o delación de la herencia, que suele coincidir con el momento de la muerte del causante. Los alieni iuris no tienen patrimonio; posteriormente, se permitió a los hijos tener peculio y también éstos pudieron causar herencia. Todo el que se pone en lugar del causante es heredero (heres). Una vez que se adquiere la cualidad de heredero, al tener un carácter personal, no se pierde. Se puede transmitir la herencia, pero esto sólo se admitió totalmente en el Derecho tardío.

Heredero puede ser cualquier persona de la familia o un extraño, pero si no es heredes suis, es heredero por aceptación de la herencia, es decir, es heredero voluntario; también puede serlo un esclavo instituido heredero al mismo tiempo que se le manumite, estos deben aceptar la herencia. Entre la delación y la aceptación puede pasar un tiempo durante el cual la herencia esté yacente en espera de ser adquirida por el heredero, siendo la tendencia la reducción de este plazo para que los bienes no puedan ser adquiridos por otro mediante usurpación.

Se llamaba herencia al conjunto patrimonial formado por la totalidad de bienes y derechos transmisibles a la muerte del causante en los que sucede el heredero. Por ello, la posición jurídica del heredero en el lugar del difunto se denomina sucesión (successio) que, en el caso de los herederos, es universal, entendiendo por tal situarse en la posición del causante (en todo lo que es transmisible, más no en las posiciones puramente personales). Esto no significa que reciba todos los bienes y derechos, porque puede recibir sólo una cuota.

Finalmente, la titularidad de heredero se puede recibir bien por una delación legal (a lo que se denomina sucesión legítima o ab intestado) o bien por voluntad del causante (sucesión testada o por testamento). Una y otra son incompatibles entre sí, de modo que cuando existen varios herederos y uno no recibe la herencia por cualquier causa, su cuota aumenta la de los demás en la misma proporción (derecho de acrecer o acrecimiento), no se considera abintestato y sólo pueden ser alteradas dichas cuotas si ha sido previsto el supuesto por el testador.

A su vez, los herederos pueden ser

- Legítimos: heredan en la sucesión abintestato. 
- Legitimarios o forzosos: los herederos legítimos que tienen derecho a impugnar un testamento que los perjudica.

- Herederos extraños: los que no estaban sometidos a la patria potestad y adquieren la herencia mediante aceptación, pudiendo deliberar sobre si aceptan o no.

En el Derecho Germánico, se desconoce el testamento y la transmisión se suele hacer por vía de donación, que será la segunda gran forma de transmisión del patrimonio en nuestro derecho. Por otra parte, a la muerte de un miembro del grupo familiar no se abre la sucesión de tipo romano, sino que el patrimonio permanece indiviso en manos de los grupos familiares cuyos miembros individualmente no pueden disponer del patrimonio familiar, especialmente de los bienes inmuebles, pudiendo disponer sólo de los muebles. A efectos sucesorios en relación con los bienes muebles, los círculos parentales se agrupan según los parientes masculinos (parientes de espada o lanza) o femeninos (parientes de rueca o huso) (véase tema 17, 1), en cuanto a los inmuebles rige el principio de troncalidad.

A partir de estos dos conceptos en torno a la sucesión, se va elaborando nuestro Derecho Sucesorio histórico, insertándose los principios germánicos en los romanos a partir del Derecho Visigótico; sobre ambos se mantendrá, cada vez con mayor poder, el Derecho Canónico.

Este cruce entre los elementos romanos, canónicos y germánicos se aprecia ya en el Derecho Sucesorio Visigótico: la disposición de bienes puede hacerse tanto por testamento como por donación, siendo uno y otro instrumento ampliamente utilizado durante este período. ${ }^{1}$

\section{Concepto de Testamento}

Es el acto jurídico personalísimo, voluntario y libre mediante el cual el causante expresa sus disposiciones de última voluntad. Además, en el derecho moderno se acepta como válidas las disposiciones de carácter no patrimonial contenidas en el testamento aun cuando éste sólo se refiere a ellos y no a sus bienes. El testamento es la declaración de última voluntad que hace una persona disponiendo de sus bienes y de asuntos que le atañen para después de su muerte. Etimológicamente, se dice que la palabra viene de Testatio Mentis, que quiere decir Testimonio de la Mente. ${ }^{2}$

Respecto al testamento preceptúa el artículo 686 del Código Civil, lo siguiente:

MORÁN MARTÍN, Remedios. Historia del Derecho Privado, Penaly Procesal. Tomo I. Parte teórica. Editorial Universitas: Madrid, 2002.

2 FERRERO, Augusto. Tratado de Derecho Civil. Tomo V. Volumen I, pág. 98. 
Por el testamento, una persona puede disponer de sus bienes, total o parcialmente, para después de su muerte, y ordenar su propia sucesión dentro de los límites de la ley y con las formalidades que esta señala. Son válidas las disposiciones de carácter no patrimonial contenidas en el testamento, aunque el acto se limite a ellas.

Cuando, a través del testamento, una persona dispone para después de su muerte, se pueden apreciar dos factores peculiares y esenciales de dicho acto. Por un lado, posee carácter imperativo, es decir, el sujeto no se limita a pedir o aconsejar, sino que ordena lo que se debe hacer según su voluntad. Por otro lado, produce efectos después de la muerte del testador, no antes. Por ello, pertenece a la categoría de los Actos Jurídicos Mortis Causa.

Respecto a la doctrina española, se define el testamento como el acto por el cual una persona dispone, para después de su muerte, de todos sus bienes o de parte de ellos. No obstante, en diversas disposiciones el Código Civil permite que en el testamento se contengan declaraciones de ultima voluntad sin contenido patrimonial, y no prohíbe que se hagan otras de esta naturaleza no tipificadas, por ejemplo, el testador manifiesta que determinado bien le pertenece privativamente a su esposa por que fue comprado con dinero de ella y no de las sociedades gananciales, o reconoce una deuda.

Para la doctrina española, según su naturaleza jurídica el testamento es un negocio jurídico toda vez que es un precepto de autonomía privada dirigido a la reglamentación de una situación jurídica la que se origina al quedar sin titular los bienes, derechos y obligaciones de su autor. ${ }^{3}$

Según la doctrina colombiana, el testamento es un acto más o menos solemne, en que una persona dispone del todo o de parte de sus bienes para que tenga pleno efecto después de sus días, conservando la facultad de revocar las disposiciones contenidas en él mientras viva. ${ }^{4}$

En razón de tales factores es que, a pesar de mediar un documento con todas las formalidades que la ley exige para que sea considerado un testamento, este no será válido si es un simple proyecto y no un acto que revista una decisión definitiva por parte del testador.

Debe pues aparecer, en el documento, la intención de testar de forma indubitable, de disponer para después de la muerte del declarante. En vida del testador, tiene el testamento el valor de un simple proyecto que únicamente adquiere perfección y logra el carácter de exigible el día en que fallezca aquél, puesto que, en este momento, habrá certeza que no podrá revocarse. 
Los pactos sucesorios por los cuales se dispone una herencia o legado están permitidos en algunas legislaciones. En países, como el nuestro, que siguen la tradición romanista, está prohibido el pacto recaído sobre el patrimonio de una persona viva que se espera obtener a través de la transmisión sucesoria, aun cuando sea el propio testador quien lo disponga en beneficio de un heredero.

\section{El Testamento Cerrado}

Alguien podría preguntarse si todavía existe el Testamento Cerrado. Según afirma Domingo Irurzun, sí existe; puesto que él recuerda haber autorizado, hace más de 50 años, uno otorgado por el registrador del distrito.

En el Seminario de Derecho Privado del Colegio Notarial de Madrid, el día 23 de octubre último el notario José María de Prada González hizo una detallada exposición de los antecedentes de lo que, en esos momentos, era el 'Anteproyecto' de Ley de Jurisdicción Voluntaria.

Convertido ya en 'proyecto', fue presentado al Congreso de los Diputados, que comenzó su tramitación, publicándolo en el Boletín Oficial de las Cortes Generales del 27 siguiente. De los 306 artículos del primero, solo quedan 202. Como novedad, se destaca la configuración de Notarios y Registradores de la Propiedad y Mercantiles como cualificados operadores jurídicos, a todos los cuales se confieren determinadas competencias en concurrencia con los Secretarios Judiciales; lo que contribuirá a dar respuesta, también en esta parcela del ordenamiento, al desafío de una justicia más ágil, racional y eficaz.

Tras expresar su favorable valoración global al mismo, continuó Prada con su exposición. Entre otras consideraciones, muy interesantes todas ellas desde el punto de vista notarial, hizo especial mención al Testamento Cerrado para poner de relieve dos aspectos del mismo: su escasa o nula frecuencia, rara especialidad, que hace dudar de su vigencia real; y las complicaciones que del mismo se derivan, no solo en el momento de su preparación y su otorgamiento, sino también en su apertura y protocolización. El proyecto le dedica los artículos 138 al 143, que constituyen el Capítulo 11 ('De la presentación, adveración, apertura y protocolización de testamentos cerrados'), del Título VIII ('Jurisdicción Voluntaria en materia de sucesiones').

Es notorio el mínimo o casi nulo uso del Testamento Cerrado autorizado por los notarios españoles. Para Manresa, es poco usado debido al gran número de formalidades exigidas para la perfección de este acto, si bien ofrece principalmente las ventajas de asegurar el secreto de 
las disposiciones testamentarias, así como la conservación del mismo testamento. Semejante parecer exponen otros autores como Corbella, Clemente de Diego, Isábal, Sánchez Román, De Buen, Valverde, Mucius Scaevola, Traviesas, Castán, O'Callaghan. Es mínimo o casi nulo el uso del Testamento Cerrado autorizado por los notarios españoles.

Más recientemente, el profesor Albaladejo considera que el Testamento Cerrado entre nosotros se da escasamente en la práctica, lo que viene motivado por tres principales razones: una, las muchas formalidades que requiere, de modo que resulta más sencillo otorgar, por ejemplo, el abierto; dos, el engorroso trámite y los gastos que suponen su apertura y protocolización; y otra, que no tiene interés el testador que se desconozca lo que ordena en su última voluntad o, aunque lo tenga, en la práctica lo mismo de desconocido permanece para los afectados lo que disponga en su Testamento Abierto cuando el propio testador y los testigos lo callan.

Acaso la común posición respecto a este tipo testamentario sea la que expresa el notario Roca Ferrer: es sabido que en España esta figura ha caído en total desuso. La liberación de las costumbres y el cambio legislativo a que ello ha dado lugar han quitado sentido a esta forma testamentaria encaminada a ocultar incluso al notario ciertas circunstancias -concubinato, hijos extramatrimoniales, dobles familias- consideradas en otros tiempos vergonzantes y hoy perfectamente toleradas, cuando no admitidas y reguladas por la propia ley. Concluye que, en más de veinticinco años de ejercicio profesional, no ha autorizado ningún Testamento Cerrado ni escritura de herencia ordenada de esta forma en uno.

El Testamento Abierto es la forma generalmente aceptada por la mayor parte de los españoles y si algún notario sabe de él, puede ser por haber recibido un ejemplar en el inventario de protocolos con ocasión de su toma de posesión, con sus sellos, plicas, firmas; y con la obligación de conservarlo a sabiendas de que, por su antigüedad, es probable que nadie lo reclame nunca, pues acaso con olvido de ese especial otorgamiento, el testador hizo otro posterior que fue el que, en definitiva, habría de regular su sucesión. Y más tarde, el autorizante, si es que el testamento le ha sido entregado y todavía lo conserva en su poder, deberá entregarlo al sucesor en la notaría, quien lo recibirá con el inventario, sin saber qué hacer con el sobre que contiene el Testamento Cerrado que se le entrega.

El Testamento Cerrado, que tiene algunas ventajas como la de permitir otorgarlo a las personas que no saben o no pueden escribir, nos llega desde el Derecho Romano, a través de Las Partidas, el Ordenamiento de Alcalá y la Ley $3^{a}$ de Toro. Tiene sus antecedentes inmediatos en el Proyecto de 1851 y en el Anteproyecto de 1888, que lo considera como uno de los tipos de "testamento común". También aparece en la Ley de Enjuiciamiento civil de 1881. 
En cuanto a la Ley del Notariado de 1862, se le cita en sus artículos 34 y 37 al libro y protocolo reservado. Su reglamento, aunque regula las actas de protocolización, nada dice respecto a la de este testamento, sin embargo alude a los protocolos y libros especiales o "especialmente reservados", con indirecta referencia a los testamentos cerrados. Roca Ferrer cree que la única vía posible de revitalizar el Testamento Cerrado es la seguida por la legislación catalana, con su entrega al notario, y, simplificando los trámites finales, elimina posibilidad de retrasos y errores que aparejen nulidad.

En algunas legislaciones llamadas "forales", hoy de ciertas Comunidades Autónomas, se contempla el Testamento Cerrado, y se suele remitir su regulación a la normativa del Código Civil. El Código de Sucesiones por causa de muerte en el Derecho civil de Cataluña, y en Aragón la Ley de Sucesiones por causa de muerte, lo recogen en su articulado. Asimismo, es aceptado por la Ley que aprueba la Compilación del Derecho Civil Foral de Navarra. En otras legislaciones, si no se cuestiona su necesidad, se remite al Código Civil la regulación del Testamento Cerrado, si bien se tiende a excluir esta normativa a medida que se afianza la respectiva legislación propia. La observancia más o menos escrupulosa de sus minuciosos requisitos ha suscitado alguna, aunque escasa jurisprudencia de nuestro Tribunal Supremo, en varias sentencias que van desde la de 6 de diciembre de 1861 hasta la de 7 de julio de 1943.

Entre otras cuestiones, trataban acerca de si la incapacidad del ciego ha de ser absoluta, o se admite si sabe leer de cualquier modo; si caben otras declaraciones escritas sobre la cubierta que lo contiene; si es válido el escrito testamentario cuando puede sustraerse de su envoltorio sin romper los sellos que cierran éste; dudas en lo que toca al cierre del documento o a la manera de salvar los errores en el escrito testamentario o en la cubierta; si el notario es responsable si actúa negligentemente o, por el contrario, se exige una mayor diligencia; y también acerca de su revocabilidad.

En este Proyecto de Ley, se prevé la modificación de determinados artículos del Código Civil, entre los cuales se encuentran algunos relativos al Testamento Cerrado; sobre su apertura y protocolización cuando se encuentra en poder del notario; presentación ante el juzgado o al notario y remisión por el agente diplomático o funcionario consular en cuyo poder se encuentre al Ministerio de Asuntos Exteriores. Hay que entender que, por tanto, los demás conservan su actual redacción y vigencia.

Pero, como ya advertía José María de Prada en su exposición, con esta modificación propuesta no se resuelven la mayoría de los problemas que puede suscitar el otorgamiento de un Testamento Cerrado, ni aún con el complemento de otros artículos que continúan vigentes. Roca Ferrer cree que la única vía posible de revitalizar el Testamento Cerrado es la seguida por la legislación catalana, con su entrega al notario, y simplificando los trámites 
finales, en especial los de apertura y protocolización, se elimina posibilidad de retrasos y errores que aparejen nulidad.

Ante estas consideraciones, cabe preguntarnos si vale la pena que esta institución no vivida siga ocupando espacio en el Código civil, aún con una nueva regulación. ¿`Tiene algún interés seguir admitiendo el Testamento Cerrado como un testamento común, según lo reconoce el vigente artículo 676? ¿No ha llegado la hora de que acompañe a otras figuras, acaso los censos, al lugar de las momias y demás antigüedades?

Porque, como dice Roca Ferrer, la conservación del Testamento Cerrado equivale a "mantener un fósil en las vitrinas de un museo". Los legisladores de 1889 no tuvieron reparo alguno en suprimir figuras jurídicas que estaban en desuso o podrían suscitar contiendas dados los requisitos que para las mismas se exigían: los censos temporales o muertos, los testamentos de confianza o por comisario, o los mancomunados en el Derecho común. Y otras, como la enfiteusis, que también estuvo a punto de caer, han sido considerablemente restringidas y condicionada.

¿No podría ocurrir lo mismo con el Testamento Cerrado? No obstante, hay que reconocer la posibilidad de que si llegara a suprimirse, desapareciendo por tanto todos los artículos del Código Civil y de este Proyecto de Ley referentes al Testamento Cerrado, algunas legislaciones autonómicas quedarían huérfanas de las normas procedimentales a las que se hace referencia en las mismas con remisión al Código civil y a la Ley de Jurisdicción Voluntaria. Pero si el Testamento Cerrado llegara a desaparecer del todo en la legislación española, es evidente que ya no harían falta estas normas de remisión.

\section{Los antecedentes de la computación}

Entre los precursores del PC, existieron hombres de ciencia y emprendedores que se unieron en torno a un punto común: el cálculo matemático. Partiendo de una era a la que podemos llamar mecánica, el hombre creó aparatos basados en el movimiento coordinado de ejes y ruedas para simplificar las 4 operaciones básicas: sumar, restar, multiplicar y dividir. Uno de ellos fue el científico alemán Wilhelm Schickard (1592-1635) quien en el año 1623 creó una máquina a la que llamó "reloj calculante", pues trabajaba con ruedas dentadas y era capaz de sumar y restar. No obstante su novedad, no se pudo fabricar completamente.

Posteriormente, sería Blaise Pascal (filósofo francés, 1623-1662) quien, en el año 1662, inventó la primera máquina automática de calcular completa a base de ruedas dentadas. Dicha máquina mostraba los resultados en una ventanilla y se la llamó Pascalina. Diez años más tarde, el filósofo y matemático alemán Gottfried Wilhelm von Leibnitz (1646-1716) mejoró 
la máquina de Pascal creando la "calculadora universal", capaz de sumar, restar, multiplicar, dividir y extraer raíces cuadradas, además de hacer la multiplicación en forma directa, en vez de realizarla por sumas sucesivas, como la máquina de Pascal.

En el año 1805, el francés Joseph Marie Jacquard (1752 -1834) dio el paso siguiente. Después de varios intentos, construyó un telar automático que efectuaba un control perfecto sobre las agujas tejedoras mediante la utilización de "tarjetas perforadas" que contenían los datos de control de las agujas. Esta máquina se puede considerar como la primera máquina mecánica programada. Se conoció como el "telar de Jacquard".

Posteriormente y dando un paso muy grande, según muchos demasiado adelantado para su época, en el año 1822 el inglés y profesor de la Universidad de Cambridge, Charles Babbage (1792-1871) diseñó la "máquina de diferencias". Su funcionamiento se basaba en mecanismos con ruedas dentadas. Podía resolver funciones y obtener tablas de las mismas. Pero las deficiencias tecnológicas de la época no permitieron su fabricación completa sino hasta años después.

No obstante las dificultades, Babbage mejoró su invento creando su segunda máquina a la que llamó "maquina analítica", un prodigio para su época pues hacía todas las operaciones con la posibilidad de ser programada por medio de tarjetas perforadas y con capacidad de almacenar una cantidad de cifras considerable. Si bien no llegó a construirse, su diseño dio origen a posteriores máquinas.

Por tal invento, se considera a Babbage el "padre de la informática", pues creó la base de la programación basada en unidades de entrada, control, calculo, memoria y salida. Por otra parte, la condesa de Lovelace, Augusta Ada Byron (1788-1824), hija del poeta Lord Byron, fue la primera persona que realizó programas para esta máquina por lo que se la ha considerado como la "primera programadora de la historia".

Más adelante, en el año 1854 y en los albores de la conmutación digital, el matemático inglés George Boole (1815-1864) desarrolló la teoría del "Álgebra de Boole" que permitió a sus sucesores el desarrollo matemático del álgebra binaria en la representación de circuitos lógicos.

Sobre el año 1885, el norteamericano y funcionario de la oficina del censo de Estados Unidos Herman Hollerith (1860-1929), al ver la tardanza en la contabilización de los datos del censo (promedio de 10 años) y luego de observar que las preguntas solo tenían como respuesta un SI o un NO, ideó un sistema de tarjetas y una máquina que las leyera para contabilizar dichos datos creando lo que él llamó la "máquina censadora o tabuladora". El 
invento permitió reducir el conteo a la tercera parte en el censo de Estados Unidos de 1890 (antes la máquina ya se había utilizado en la tabulación estadística de mortalidad en Baltimore en 1887).

Posteriormente, adicionó a su máquina la función de sumar y la ofreció a la empresa de los Ferrocarriles Centrales de Nueva York. Tal iniciativa se constituyó en el primer intento de realización automática de una aplicación comercial. El invento de Hollerith le permitió fundar la empresa Tabulating Machines Company (1896) la que, en 1924, se fusionó con otras dando origen a la Intenational Bussines Machines (IBM), a cuya cabeza estuvo Thomas J. Watson (padre).

Después de la creación de Hollerith, se crearon máquinas que utilizaron sus principios entre las que se destacan la calculadora "la millonaria", creada por el suizo Otto Steiger en 1893 y considerada como la primera calculadora que tuvo éxito comercial. El ingeniero español Leonardo Torres Quevedo (1852-1936) construyó, a principios del siglo XX, varias máquinas automáticas teledirigidas, una máquina para jugar ajedrez y una calculadora. En 1936, el matemático inglés Alan M. Turing (1912-1954) desarrolló la teoría de una máquina capaz de resolver todo tipo de problemas mediante una solución algorítmica. Esta teoría se conoce hoy como la Máquina de Turing y es básica comprenderla en la programación.

En 1937, Howard H. Aiken de la Universidad de Harvard, en asociación con un grupo de científicos universitarios e ingenieros de IBM, crea una calculadora numérica basada en el uso de relés electromagnéticos, ruedas dentadas y embragues electromecánicos dando origen a la que se puede considerar como la primera computadora electromecánica.

Se la denominó Mark-I y utilizaba medios de entrada tarjetas y cinta perforadas que procesaba en unidades aritméticas, unidad de control y una unidad de memoria. Se terminó de construir en 1944 y a pesar de que funcionó bien, fue rápidamente superada por las computadoras electrónicas que aparecieron a casi a la par que su construcción. ${ }^{5}$

\section{Definición de Documento Electrónico}

En términos amplios, debe entenderse por documento o instrumento a cualquier objeto que contiene una información, que narra, hace conocer o representa un hecho, cualquiera sea su naturaleza, su soporte o "continente", su proceso de elaboración o su tipo de firma. Los elementos propios de esta noción amplia son la existencia de un soporte en que constan, un medio que se emplea para grabar los signos, un lenguaje o idioma y un mensaje o "contenido".

PINOCHET OLAVE, Ruperto. "El documento electrónico y la prueba literal”, en: Ius et Praxis, 2002, vol. 8, No 2, p. 377-412. 
Entonces de la noción amplia de documento se puede decir que éste se encuentra formado por dos elementos: a) un elemento material o soporte físico y b) un elemento intelectual o representación de una determinada realidad.

Asimismo, en el ámbito jurídico, dentro de los exponentes clásicos de la noción amplia de documento encontramos a Carnelutti, quien entiende por documento; "una cosa representativa, o sea capaz de representar un hecho", o como explica el autor citado, representación es la imagen de la realidad, la que se presenta al intelecto a través de los sentidos; y en, consecuencia, documento es una cosa que sirve para representar a otra. Continúa señalando Carnelutti que la representación de un hecho, y no la manifestación del pensamiento, es la nota esencial al concepto de documento. ${ }^{6}$

En un sentido restringido, con la expresión documento sólo se reconocen a aquellos objetos que están escritos en soporte papel y rubricados o firmados manualmente. La firma podemos definirla como un trazado gráfico que habitualmente contiene el nombre, apellido y la rúbrica de una persona, mediante el cual se suscriben los documentos para darle autoría y obligarse a cumplir con lo que en ellos se dice. De forma más simple, se ha dicho que es el conjunto de letras o signos que identifican a la persona que la estampa en un documento o texto.

Atendiendo a su origen, los documentos podemos clasificarlos en públicos o privados. Tienen esta segunda naturaleza aquellos que dejan constancia de un hecho sin solemnidad alguna, en cuyo otorgamiento no interviene un funcionario en calidad de tal, y que no llevan en si ningún sello de autenticidad.

El documento electrónico debe entenderse como toda expresión en lenguaje natural o convencional y cualquier otra expresión gráfica, sonora o en imagen, recogidas en cualquier tipo de soporte material, incluso los soportes informáticos, con eficacia probatoria o cualquier otro tipo de relevancia jurídica. De manera general, se puede definir como el documento en cuya elaboración ha intervenido la tecnología informática. El documento, en efecto, puede quedar plasmado en forma digital y contenido en la memoria central del computador o en las memorias en masa (diskkettes, cintas magnéticas, DVD). Estos son los documentos electrónicos en sentido estricto, cuya característica común es que no pueden ser leídos o conocidos por el hombre sino como consecuencia de la intervención de adecuadas máquinas traductoras que hacen perceptibles y comprensibles a los sentidos del hombre las señales digitales de las que están constituidos.

6 Idem. 
Los documentos electrónicos poseen los mismos elementos que un documento escrito en soporte papel: a) constan en un soporte material (cintas, diskettes, circuitos, chips de memoria, redes); b) contiene un mensaje, el que esta escrito usando el lenguaje convencional de los dígitos binarios o bits, entidades magnéticas que los sentidos humanos no pueden percibir directamente; c) están escritos en un idioma o código determinado; d) pueden ser atribuidos a una persona determinada en calidad de autor mediante una firma digital, clave o llave electrónica.

Es así que para dar seguridad a los documentos electrónicos, se ha ideado una manera en la que podría sellarse el documento y esto sería mediante la llamada firma electrónica. Bien mirado, se trata de un modo de suscripción que cumple de igual e incluso de mejor manera la autenticación de las partes, el cual se da por la imposibilidad de efectuar un trazado gráfico. En efecto, la única manera de escribir sobre un documento electrónico es a través de una secuencia lógica de unos y ceros, lo que ciertamente descarta a un trazado gráfico.

La consecuencia de que la firma electrónica otorgue efectos jurídicos al documento electrónico se debe a que la firma electrónica permite que éstos sean "fiables". En efecto, la firma electrónica soluciona los problemas que se derivan del tratamiento electrónico de datos, en particular, la facilidad con la cual pueden ser adulterados, copiados, y la imposibilidad que se tiene de conocer con cierta seguridad de la autoría del contenido de tal documento. Este fue uno de los grandes frenos para el reconocimiento jurídico del documento electrónico.

Surgen, en consecuencia, principios que deben cumplir una firma electrónica a fin de estar frente a un documento electrónico que pudiéramos denominar "fiable". Primero, la firma electrónica debe garantizar la autenticidad, es decir, la identidad de las partes que intervienen en una transacción y por ende la autoría del documento en referencia. Por otra parte, es preciso que la firma electrónica tutele la integridad del documento electrónico, es decir, que el contenido de éste no sea alterado por terceros. Como consecuencia de lo anterior, el autor de un documento electrónico luego de emitir tal documento a un tercero o contraparte no puede negar su envío y contenido (No repudio o no rechazo). Un cuarto requerimiento que generalmente acontece es la confidencialidad. Ella, desde la perspectiva de las comunicaciones, asegura que un documento electrónico remitido por medios electrónicos pueda ser leído o utilizado por quien esté autorizada para ello. ${ }^{7}$

\section{El DVD (disco de video digital), conformación y flexibilidad}

El DVD (también conocido como "Digital Versatile Disc” o "Disco Versátil Digital”, aunque también se le puede denominar como "Digital Video Disc" o "Disco de Video 
Digital") es un formato multimedia de almacenamiento óptico que puede ser usado para guardar datos, incluyendo películas con alta calidad de vídeo y audio. Se asemeja a los discos compactos en cuanto a sus dimensiones físicas (diámetro de $12 \mathrm{u} 8 \mathrm{~cm}$ ), pero están codificados en un formato distinto y a una densidad mucho mayor. A diferencia de los CD, todos los DVD deben guardar los datos utilizando un sistema de archivos denominado UDF, el cual es una extensión del estándar ISO 9660, usado para CD de datos.

El DVD usa un método de codificación más eficiente en la capa física: los sistemas de detección y corrección de errores utilizados en el $\mathrm{CD}$, como la comprobación de redundancia cíclica CRC, la codificación Reed-Solomon, RS-PC, así como la codificación de línea Eightto-Fourteen Modulation, la cual fue reemplazada por una versión más eficiente, EFMPlus, con las mismas características que el EFM clásico. El subcódigo de CD fue eliminado. Como resultado, el formato DVD es un $47 \%$ más eficiente que el CD-ROM, que usa una tercera capa de corrección de errores.

Los DVD se pueden clasificar de acuerdo a su contenido en:

- DVD-Video: (vídeo y audio)

- DVD-Audio: Audio de alta definición

- DVD-Data: Datos cualesquiera

El disco puede tener una o dos caras, y una o dos capas de datos por cada cara; el número de caras y capas determina la capacidad del disco. Los formatos de dos caras apenas se utilizan. Se puede grabar la acción en una-toma continúa o en distintas sesiones tomando las consecuencias una a una y uniéndolas después como si fuera una producción continúa. El DVD puede ser utilizado como material de estudio de revisión y naturalmente como archivo.

\section{Conclusiones}

Se puede decir que un testamento es el único instrumento mediante el cual se expresa de manera jurídicamente válida esa voluntad de disponer los bienes para después de la muerte, por lo que se hace necesario dejar testamento a sus descendientes.

En la figura del testamento es el mismo causante el que dispone de la herencia, decidiendo sobre los bienes que son repartidos a sus herederos.

El régimen testamentario en nuestro país es muy poco utilizado, ya que al examinar su normativa, se puede apreciar que desde el punto de vista documental se caracteriza por su 
rigidez formal, lo que determina que la utilidad social del testamento resulte mínima y por lo tanto de poco uso.

El testamento, una vez otorgado, disfruta de la presunción de validez, y mientras por la justicia ordinaria no haya sido declarado total o parcialmente nulo, producirá efectos pretendidos. Mediante una investigación técnica del uso del DVD, se ha determinado que éste puede durar fácilmente cien años, lo cual hace viable otorgar testamento mediante esta modalidad y su uso como documento electrónico.

El video, por tener un uso frecuente y cotidiano en la actualidad, ayudaría a que la población tenga más acceso a la utilización de la figura del testamento como un medio de transmisión de la herencia

El testamento otorgado mediante la modalidad de DVD posee garantías de autenticidad, ya que el mismo causante será el que manifieste su última voluntad, la cual estará bajo la custodia del notario, quien se encargará de su conservación siendo mantenido en secreto bajo la modalidad de testamento cerrado.

La seguridad jurídica que debe revestir el uso del DVD se encuentra enmarcada dentro de la modalidad de Testamento Cerrado a fin de hacer más accesible al causante y a sus herederos el uso de esta figura tomando en cuenta que, en nuestra sociedad, los procesos de comunicación audiovisual ocupan un importante lugar en la realidad sociocultural contemporánea.

De modificarse el artículo del Código Civil y considerar que se puede otorgar testamento mediante la modalidad electrónica, este recibiría el nombre de Testamento Cerrado Electrónico.

\section{Recomendaciones}

Se debe incorporar, a nuestra normatividad sustantiva, figuras acorde a los adelantos tecnológicos.

Se debe modificar artículos, en nuestra normatividad adjetiva, e introducir la permisión de procedimientos acorde a los adelantos científicos.

No solo los actos notariales de otorgamiento de Testamento Cerrado, sino también de Escritura Pública deberían estar en el nivel de la tecnología.

Deberían abrirse espacios académicos para la discusión sobre la importancia de la tecnología con relación a los actos jurídicos. 
El Colegio de Abogados debería de promover talleres de tecnologías al alcance de la práctica del derecho como se viene desarrollando con los fedatarios digitales.

\section{Bibliografía}

- AGUADO, Eustorgio. Derecho de Sucesiones. Grupo Editorial Leyer: Santa Fe de Bogotá, 2000.

- CRESPO VIÑEGRA, Julio. DVD, DIVX y otros formatos de video digital. Anaya Multimedia: Madrid, 2003.

- DIEZ, Luis. Sistema de Derecho Civil. Volumen IV. Tecnos: Madrid, 1997.

- FERNANDEZ ACEVEDO, Fernando J. "El documento electrónico en el derecho civil chileno. Análisis de la ley 19.799” en: Ius et Praxis, 2004, Vol. 10, n² 2. pag. 137-167.

- FERRERO, Augusto. Tratado de Derecho Civil, Tomo V, Vol. I, 2001, Cultural Cuzco : Lima.

- MESSINEO, Francesco. Manual de Derecho Civil y Comercial, Tomo VII. Ediciones Jurídicas Europa - América : Buenos Aires, 1956.

- PALACIO, Gustavo. Manual de Derecho Civil. Tomo I, Cultural Cuzco : Lima, 1985.

- PARKER, Charles S. Biblioteca Temática de la Informática. Madrid, 1986.

- PEÑARANDA QUINTERO Hector, Iuscibernética: Interrelación entre el Derecho y la Informática. Ediciones Maracaibo: Zulia, 2006.

- PINOCHET OLAVE, Ruperto. "El documento electrónico y la prueba literal”, en: Ius et Praxis, 2002, Vol 18, n 2. pag. 397-412.

- REMEDIOS MORÁN, Martín. Universitas, Historia del Derecho Privado, Penal y Procesal. Editorial Universitas: Madrid, 2002.

- ZANONNI A, Eduardo. Manual del Derecho de Sucesiones. Palestra Editores: Bs.As., 1998.

- ZARATE DEL PINO, Juan B. Curso de Derecho de Sucesiones. Astrea: Lima, 1980. 


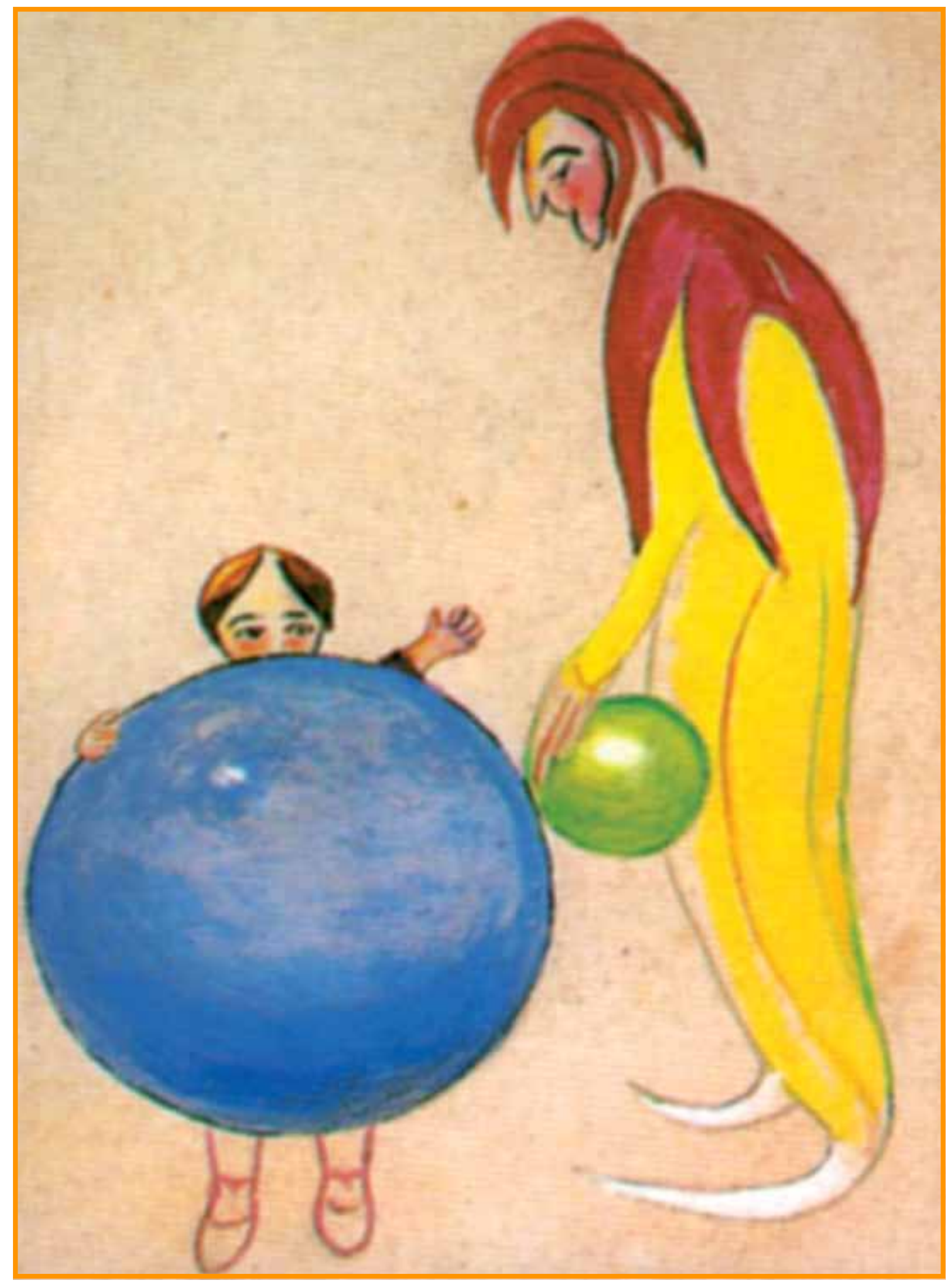

Juventud - vejez 